\title{
Penentuan Faktor Prioritas Pemilihan Online Travel Agency di Wilayah Bekasi Menggunakan Metode Analytical Hierarchy Process
}

\author{
Syifa Nur Rakhmah, Sri Wahyuningsih* \\ Prodi Sistem Infrmasi, STMIK Nusa Mandiri, Jakarta, Indonesia \\ Email: ${ }^{1}$ syifa.snk@ nusamandiri.ac.id, 1," swahyuningsih16@gmail.com \\ Email Penulis Korespondensi: swahyuningsih16@gmail.com
}

\begin{abstract}
Abstrak-Online travel agency adalah salah satu produk kemajuan jaman yang sedang booming saat ini. Dengan kemunculan online travel agent, penggunaan online travel di Indonesia kini mulai diminati. Banyaknya kemudahan dan kelebihan yang ditawarkan oleh online travel, maka pelanggan dituntut jeli untuk memilih online travel agency. Penelitian ini dilakukan untuk mengukut efektivitas online travel yang dipilih oleh pelanggan. Dengan menggunakan kriteria pada ISO 9001:2008 faktor yang mempengaruhi kepuasan pelanggan diantaranya yaitu Service Quality, Product Quality, Price, Situasional Factor dan Personal Factor. Penelitian ini dilakukan pada pelanggan online travel di wilayah Kota Bekasi yang jumlah penduduknya sebanyak 3.013.851 jiwa dengan perhitungan menggunakan rumus Slovin didapatkan jumlah sampel 400 responden. Metode yang digunakan yaitu analytical hierarchy process. Hasil penelitian ini menunjukkan bahwa yang menjadi alternative pertama adalah Traveloka dengan nilai bobot 1,961 atau 47,6\% kemudian Tiket.com dengan nilai bobot 1,018 atau 27,7\% dan yang terakhir Pegipegi dengan nilai bobot 1,141 atau $24,7 \%$ dan untuk kriteria yang menjadi daya tarik pelanggan dalam memilih online travel yaitu Service Quality 27,7\%, Product Quality 24,1\%, Price 22,9\%, Personal Factor 15,5\% dan Situasional Factor 9,8\%.
\end{abstract}

Kata Kunci: Online Travel Agency, ISO 9001:2008, Analytical Hierarchy Process, Tiket,

\begin{abstract}
Online travel agent is one of the products of the advancing era that is currently booming. With the advent of online travel agents, the use of online travel in Indonesia is now beginning to be demand. The many conviences and advantages offered bya online travel, then customers are required to be keen to choose an online travel agency. This research was conductes to measure the effectivieness of online travel chosen by customers. By using the criteria in ISO 9001:2008 factors that influence customers satisifaction include Service Quality, Product Quality, Price, Situasional Quality and Personal Quality. This research was conducted on online travel customers in the City of Bekasi area with a population of 3,013,851 inhabitants with calculations using the Slovin formula obtained a sampel size 400 respondents. The metod use is the analytical hierarchy process. The results of this study indicate that the first alternative is Traveloka eit a weight value of 1.916 or $47.6 \%$, then Tiket.com with a weight value of 1.018 or $27.7 \%$ and finnaly Pegipegi with a weight value of 1.141 or $24.7 \%$ and for criteria the main attraction customers in chossinh online travel is Service Quality 27.7\%, Procust Quality 24.1\%, Price 22.9\%, Personal Factor $15.5 \%$ and Situasional Factor $9.8 \%$.
\end{abstract}

Keywords: Online Travel Agency, ISO 9001:2008, Analytical Hierarchy Process, Ticket, Bekasi

\section{PENDAHULUAN}

Menjelajahi wilayah baru atau saat ini masayarakat lebih mengenal dengan istilah travelling dimana merupakan salah satu aktivitas yang kini telah menjadi salah satu perilaku gaya hidup masyarakat Indonesia. Tidak hanya sekedar berpergian, kini masyarakat Indonesia ingin melakukan perjalanan lebih lama, lebih jauh dan lebih sering (longer, farther, and more often). Berdasarkan hasil Global Travel Intentions Study (GTIS) tahun 2015 yang dikeluarkan oleh Visa [1] menyebutkan bahwa 85 persen responden Indonesia telah melakukan perjalanan wisata internasional dalam dua tahun terakhir [2]. Hal ini juga didukung dengan penelitian Bain and Company, disebutkan layanan terbesar yang paling banyak dimanfaatkan oleh konsumen di Asia Tenggara, yaitu layanan pariwisata dan layanan perjalanan wisata sebesar \$22 miliar, diikuti dengan layanan e-commerce sebesar \$15 miliar dan media serta hiburan sebesar \$3 miliar. Dengan meningkatnya minat masyarakat Indonesia dalam melakukan perjalanan wisata, maka para pelaku usaha melihat adanya peluang dalam bisnis travel sehingga mulai tergerak untuk membangun startup dibidang online travel agent (OTA) [1] .

Online travel agent adalah salah satu produk kemajuan jaman yang sedang booming saat ini [3] [2]. Dengan kemunculan online travel agent, penggunaan online travel di Indonesia kini mulai diminati. Berdasarkan hasil survey dailysocial.id bersama Jakpat Mobile Survey Platform pada tahun 2018 mencatat bahwa 71,44 persen responden telah menggunakan layanan online travel agency untuk keperluan pemesanan tiket perjalanan. Hasil lain juga menunjukkan bahwa terdapat sebanyak 83,95 persen dari keseluruhan responden menggunakan smartphone untuk mengakses layanan online travel agency dan 69,26 persen responden melakukan pembayaran melalui transfer bank maupun ATM.

Online travel agency pada dasarnya memiliki ruang lingkup bisnis selayaknya agen konvensional. Hanya saja, online travel agency membuka layanan berbasis digital, dimana transaksi pemesanan, pencarian informasi, dan pembayaran semuanya terjadi secara online. Beberapa contoh online travel agency yang ada di Indonesia adalah Traveloka, Pegipegi, Tiket.com, dan masih banyak lagi. Menurut hasil survey dailysocial.id bersama Jakpat Mobile Survey Platform pada tahun 2018 menyebutkan alasan seseorang menggunakan online travel agency adalah banyaknya promosi yang digunakan sebesar 45,04 persen, memberikan harga termurah sebesar 16,57 persen dan kemudahan saat digunakan sebesar 12,32 persen. 
Namun disisi lain masih terdapat konsumen yang masih mengalami kesulitan ketika menggunakan online travel agent. Berdasarkan situs mediakonsumen.com menyebutkan terdapat konsumen yang mengalami kesulitan ketika melakukan pembelian tiket perjalanan melalui salah satu online travel agency, karena tidak terbitnya $e$ ticket ketika sudah melakukan pembayaran. Selain itu terdapat juga ketidak amanan pada fasilitas Paylater dikarenakan adanya penyalah gunaan akun yang dirasakan oleh beberapa konsumen. Hal lain yang menjadikan permasalahan dalam penelitian kali ini adalah adanya peningkatan minat menggunakan online travel agency, terdapat kesulitan ketika menggunakan online travel agency, kurangnya keamanan pada fasilitas Paylater, selain itu adanya faktor-faktor yang mempengaruhi ketika memilih online travel agency sebagai dampak dari pemilihan online travel.

Meskipun adanya ketidakpuasan yang dirasakan, tapi masih banyak masyarakat yang tertarik untuk menggunakan online travel agent. Hal ini terjadi karena ada beberapa faktor yang mempengaruhi masyarakat dalam penggunaan online travel agency. Berdasarkan fenomena tersebut, maka peneliti tertarik untuk meneliti tentang sistem penunjang keputusan terhadap efektifitas penggunaan online travel agency menggunakan metode Analytical Hierarchy Process.

Dalam penelitian kali ini, penulis membatasi pembahasan yang diangkat berkaitan kriteria pemilihan media online travel agency berdasarkan kriteria ISO 9001:2008 [4], yaitu diantaranya kualitas pelayanan, kualitas produk, harga, faktor situasional dan faktor pribadi. Pengambilan data primer didapatkan dari penyebaran kuesioner kepada responden yang telah melakukan transaksi menggunakan online travel agency. Dalam hal ini penulis membatasi pada online travel agency yang diteliti, yaitu Traveloka, Pegipegi, dan Tiket.com.

Adapun wilayah yang dijadikan pengambilan data kuesioner adalah wilayah Kota Bekasi. Dimana jumlah total populasi responden diambil dari jumlah penduduk wilayah Kota Bekasi pada tahun 2019, yaitu sejumlah 3.013.851 jiwa (Sumber: Badan Pusat Statistik) dan penentuan jumlah responden diperoleh menggunakan rumus Slovin 5 persen sehingga didapatkan jumlah responden sebanyak 400 orang. Metode yang digunakan adalah Analytical Hierarchy Process dan untuk pengolahan data menggunakan Software Expert Choice.

Berdasarkan penelitian sebelumnya yang telah dilakukan [5] [6] [3] online travel agency hanya dilakukan pengujian pada salah satu travel agent saja yaitu traveloka serta kriteria yang digunakan sebagai media penilaian hanya dua yaitu harga dan kualitas layanan. Hasil dari penelitian sebelumnya menyebutkan jika kedua variable sangat berpengaruh dalam pemilihan fasilitas yang ada pada penyedia jasa online travel agency. Oleh sebab itu, penulis ingin lebih menjabarkan lebih rinci, agar penyedia jasa online travel agency yang lainnya juga bisa di nilai dan melihat penilaiannya dari berbagai macam kriteria variable yang sesuai dengan ISO 9001:2008 [4].

Penelitian ini kedepannya juga bertujuan agar nantinya dapat mengetahui efektifitas online travel agency yang dirasakan oleh Masyarakat Bekasi. Selanjutnya mengetahui daya minat Masyarakat Bekasi dalam menggunakan online travel agency. Mengetahui faktor utama ketika masyarakat Bekasi memilih online travel agency yang digunakan. Serta mengetahui efektifitas metode Analytical Hierarchy Process sebagai sistem penunjang keputusan dalam memilih online travel agency [7]. Penelitian kali ini menggunakan metode Analytical Hierarchy Process dikarenakan sejauh ini belum ada penelitian yang mengangkat tentang fenomena OTA di masyarakat, seperti halnya penelitian-penelitian yang dijadikan referensi oleh penulis [8] [9] [10] dimana penelitian sebelumnya mengangkat tentang transportasi online dengan menggunakan metode Analytical Hierarchy Process sebagai penunjang keputusannya.

\section{METODOLOGI PENELITIAN}

\subsection{Tahapan Penelitian}

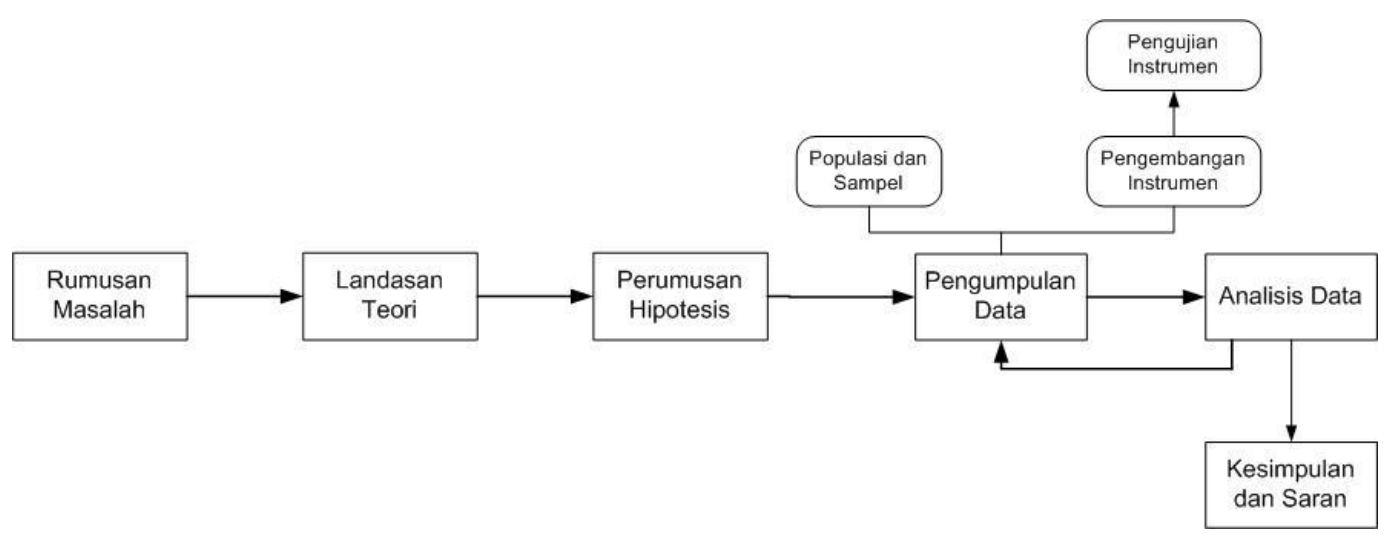

Gambar 1. Tahapan Penelitian

Pada penelitiian ini penulis menggunakan metode Analytical Hierarchy Process dengan melakukan beberapa tahapan penelitian sebagai berikut:[11]

a. Rumusan Masalah 
Langkah pertama yang dilakukan dalam penelitian ini adalah mengidentifikasi masalah yang ada, kemudian dilakukannya perumusan masalah sehingga dapat menentukan tujuan yang akan dicapai pada penelitian ini.

b. Landasan teori

Berdasarkan rumusan masalah yang ada, tahapan selanjutnya mempelajari literatur yang berhubungan dengan permasalahan yang diteliti yang akan menjadi landasan teori pada penilitian. Sumber literatur didapatkan dari perpustakaan, jurnal nasional, artikel, yang membahas tentang metode Analytical Hierarchy Process, Online Travel Agency serta bahan bacaan lainnya yang dapat mendukung penelitian.

c. Perumusan Hipotesis

Berdasarkan rumusan masalah yang telah ditentukan dan landasan teori yang dikumpulkan maka selanjutnya penentuan hipotesis yang digunakan sebagai jawaban sementara terhadap rumusan masalah.

d. Pengumpulan Data

Pengumpulan data dilakukan dengan menggunakan penyebaran kuesioner kepada pengguna online travel agency yang terdapat di Kota Bekasi. Berdasarkan data kuesioner yang terkumpul, maka akan diadakannya uji validitas dan reabilitas guna membuktikan instrumen yang dipakai valid dan reliabel.

e. Analisis Data

Analis data dapat dilakukan ketika instrumen penelitian telah terbukti valid dan reliabel. Data yang valid dan reliabel kemudian diolah menggunakan metode analytical hierarchy process, kemudian dianalis kekonsitensian data yang diperoleh.

f. Kesimpulan dan Saran

Pada tahapan akhir ini maka akan diambil kesimpulan berdasarkan data-data yang telah diolah dari tahapantahapan sebelumnya. Kesimpulan berisi tentang urutan kriteria, sub kriteria, dan alternatif yang paling diminati oleh masyarakat Kota Bekasi. Selain kesimpulan terdapat juga saran untuk peneliti selanjutnya yang ingin meneruskan penelitian ini.

\subsection{Metode Pengumpulan Data, Populasi dan Sampel Penelitian}

a. Metode Pengumpulan Data

Metode pengumpulan data yang digunakan oleh penulis adalah kuesioner. Kuesioner yang digunakan adalah angket yang disajikan dalam bentuk sedemikian rupa sehingga responden diminta untuk memilih jawaban yang sesuai dengan karakteristik dirinya dengan memberikan tanda silang (x) atau tanda checklist $(\sqrt{ })$.

Tabel berikut merupakan tabel perbandingan berpasangan yang diujikan:

Tabel 1. Perbandingan Kriteria Utama

Dalam Sistem Pendukung Keputusan untuk Menentukan Jasa

Online Travel Agency yang diinginkan, Kriteria Manakah yang Lebih Penting Dibandingkan Kriteria-Kriteria Berikut?

\begin{tabular}{|c|c|c|}
\hline Kualitas Pelayanan & Kualitas Produk & (1) $23(4)$ \\
\hline Kualitas Pelayanan & Harga & \\
\hline Kualitas Pelayanan & Faktor Situasional & \\
\hline Kualitas Pelayanan & Faktor Pribadi & \\
\hline Kualitas Pelayanan & Harga & \\
\hline Kualitas Produk & Faktor Situasional & \\
\hline Kualitas Produk & Faktor Pribadi & \\
\hline Harga & Faktor Situasional & \\
\hline Harga & Faktor Pribadi & \\
\hline Faktor Situasional & Faktor Pribadi & \\
\hline
\end{tabular}

b. Populasi

Populasi yang dipakai pada penelitian ini adalah masyarakat Kota Bekasi sebanyak 3.013.851 jiwa (Sumber: BPS Kota Bekasi). Berdasarkan sumber penelitian daylisocial.id bahwa terdapat 50 persen penduduk Indonesia yang menggunakan Traveloka dan/atau Tiket.com. Maka didapatkan populasi untuk penelitian ini sebagai berikut:

Populasi $=$ Populasi Kota Bekasi $\times 50 \%$

$=3.013 .851 \times 50 \%$

$=1.506 .926$ jiwa. 


\section{JURNAL MEDIA INFORMATIKA BUDIDARMA}

Volume 4, Nomor 3, Juli 2020, Page 825-833

ISSN 2614-5278 (media cetak), ISSN 2548-8368 (media online)

Available Online at https://ejurnal.stmik-budidarma.ac.id/index.php/mib

DOI 10.30865/mib.v4i3.2268

c. Sample Penelitian

Pengambilan sampel dalam penelitian ini adalah menyebar kuesioner kepada masyarakat yang menggunakan online travel agent. Berdasarkan rumus Slovin [12] dengan tariff kesalahan 5\% maka diperoleh sampel sebagai berikut:

$$
\begin{aligned}
\mathrm{n} & =\frac{N}{1+N e^{2}} \\
& =\frac{1506926}{1+\left(1506926 \times 0.05^{2}\right)} \\
& =\frac{1506926}{37568,315} \\
& =399,89 \text { dibulatkan menjadi } 400
\end{aligned}
$$

\subsection{Metode Analisis Data}

Dalam menguji data hasil kuesioner yang telah terkumpul, penulis menggunakan dua pengujian yaitu uji validitas dan uji reabilitas. [13]

a. Uji Validitas

Tabel 2. Uji Validitas

\begin{tabular}{|c|c|c|c|c|c|c|c|c|c|}
\hline Nilai & $\begin{array}{c}\text { Varian } \\
\text { Skor }\end{array}$ & $\begin{array}{c}\text { Varian } \\
\text { Total }\end{array}$ & Alpha & Ket & Nilai & $\begin{array}{c}\text { Varian } \\
\text { Skor }\end{array}$ & $\begin{array}{c}\text { Varian } \\
\text { Total } \\
\end{array}$ & Alpha & Ket \\
\hline $\mathrm{S} 1$ & 4.65 & & & reliabel & S24 & 4.39 & & & reliabel \\
\hline $\mathrm{S} 2$ & 2.54 & & & reliabel & $\mathrm{S} 25$ & 5.47 & & & reliabel \\
\hline $\mathrm{S} 3$ & 9.96 & & & reliabel & S26 & 4.85 & & & reliabel \\
\hline $\mathrm{S} 4$ & 6.16 & & & reliabel & $\mathrm{S} 27$ & 4.92 & & & reliabel \\
\hline S5 & 1.94 & & & reliabel & $\mathrm{S} 28$ & 5.76 & & & reliabel \\
\hline S6 & 4.64 & 2714,73 & 0,936 & reliabel & $\mathrm{S} 29$ & 4.13 & 2714,73 & 0,936 & reliabel \\
\hline S7 & 3.85 & & & reliabel & S30 & 4.24 & & & reliabel \\
\hline S8 & 7.08 & & & reliabel & S31 & 6.34 & & & reliabel \\
\hline S9 & 4.71 & & & reliabel & S32 & 4.18 & & & reliabel \\
\hline S10 & 4.91 & & & reliabel & S33 & 4.20 & & & reliabel \\
\hline S11 & 4.94 & & & reliabel & S34 & 6.28 & & & reliabel \\
\hline
\end{tabular}

\begin{tabular}{cccccccc}
\hline Instrumen & r hitung & r tabel & keterangan & Instrument & r hitung & r tabel & keterangan \\
\hline 1 & 0,360 & 0,098 & valid & 24 & 0,595 & 0,098 & valid \\
2 & 0,352 & 0,098 & valid & 25 & 0,492 & 0,098 & valid \\
3 & 0,414 & 0,098 & valid & 26 & 0,592 & 0,098 & valid \\
4 & 0,442 & 0,098 & valid & 27 & 0,586 & 0,098 & valid \\
5 & 0,376 & 0,098 & valid & 28 & 0,472 & 0,098 & valid \\
6 & 0,381 & 0,098 & valid & 29 & 0,615 & 0,098 & valid \\
7 & 0,318 & 0,098 & valid & 30 & 0,599 & 0,098 & valid \\
8 & 0,352 & 0,098 & valid & 31 & 0,499 & 0,098 & valid \\
9 & 0,332 & 0,098 & valid & 32 & 0,611 & 0,098 & valid \\
10 & 0,255 & 0,098 & valid & 33 & 0,601 & 0,098 & valid \\
11 & 0,483 & 0,098 & valid & 34 & 0,501 & 0,098 & valid \\
12 & 0,477 & 0,098 & valid & 35 & 0,603 & 0,098 & valid \\
13 & 0,416 & 0,098 & valid & 36 & 0,576 & 0,098 & valid \\
14 & 0,628 & 0,098 & valid & 37 & 0,502 & 0,098 & valid \\
15 & 0,611 & 0,098 & valid & 38 & 0,605 & 0,098 & valid \\
16 & 0,513 & 0,098 & valid & 39 & 0,562 & 0,098 & valid \\
17 & 0,599 & 0,098 & valid & 40 & 0,500 & 0,098 & valid \\
18 & 0,585 & 0,098 & valid & 41 & 0,626 & 0,098 & valid \\
19 & 0,478 & 0,098 & valid & 42 & 0,610 & 0,098 & valid \\
20 & 0,622 & 0,098 & valid & 43 & 0,488 & 0,098 & valid \\
21 & 0,570 & 0,098 & valid & 44 & 0,597 & 0,098 & valid \\
22 & 0,489 & 0,098 & valid & 45 & 0,595 & 0,098 & valid \\
23 & 0,621 & 0,098 & valid & 46 & 0,488 & 0,098 & valid \\
\hline
\end{tabular}

b. Uji Reabilitas

Tabel 3. Uji Reabilitas 
JURNAL MEDIA INFORMATIKA BUDIDARMA

Volume 4, Nomor 3, Juli 2020, Page 825-833

ISSN 2614-5278 (media cetak), ISSN 2548-8368 (media online)

Available Online at https://ejurnal.stmik-budidarma.ac.id/index.php/mib DOI $10.30865 / \mathrm{mib} . v 4 \mathrm{i} 3.2268$

\begin{tabular}{|c|c|c|c|c|c|c|c|c|c|}
\hline Nilai & $\begin{array}{c}\text { Varian } \\
\text { Skor }\end{array}$ & $\begin{array}{c}\text { Varian } \\
\text { Total }\end{array}$ & Alpha & Ket & Nilai & $\begin{array}{c}\text { Varian } \\
\text { Skor }\end{array}$ & $\begin{array}{c}\text { Varian } \\
\text { Total }\end{array}$ & Alpha & Ket \\
\hline S12 & 4.51 & & & reliabel & S35 & 4.76 & & & reliabel \\
\hline S13 & 5.12 & & & reliabel & S36 & 4.73 & & & reliabel \\
\hline S14 & 4.73 & & & reliabel & S37 & 5.80 & & & reliabel \\
\hline S15 & 4.48 & & & reliabel & S38 & 4.46 & & & reliabel \\
\hline S16 & 4.62 & & & reliabel & S39 & 4.10 & & & reliabel \\
\hline S17 & 4.74 & & & reliabel & S40 & 5.62 & & & reliabel \\
\hline S18 & 4.61 & & & reliabel & S41 & 4.22 & & & reliabel \\
\hline S19 & 6.28 & & & reliabel & $\mathrm{S} 42$ & 4.44 & & & reliabel \\
\hline S20 & 4.61 & & & reliabel & S43 & 5.63 & & & reliabel \\
\hline $\mathrm{S} 21$ & 4.63 & & & reliabel & S44 & 5.05 & & & reliabel \\
\hline $\mathrm{S} 22$ & 6.14 & & & reliabel & $\mathrm{S} 45$ & 4.96 & & & reliabel \\
\hline $\mathrm{S} 23$ & 4.66 & & & reliabel & S46 & 5.78 & & & reliabel \\
\hline
\end{tabular}

\section{HASIL DAN PEMBAHASAN}

Dari penelitian ini dibuat dengan AHP sebagai suatu sistem pendukung keputusan untuk pemilihan online travel agency di wilayah Bekasi. Data penelitian diperoleh dari kuesioner yang diisi oleh 400 responden pengguna travel online. Kriteria yang digunakan yaitu kualitas pelayanan, kualitas produk, harga, faktor situasional, faktor pribadi. Untuk sub kriteria dari kualitas pelayanan yaitu memiliki tampilan yang mudah dimengerti, cepat dalam menanggapi keluhan pelanggan dan memberikan informasi secara jelas dan mudah dimengerti. Untuk sub kriteria harga yaitu memberikan potongan harga dan memberikan cashback. Untuk sub kriteria faktor situasional yaitu kemudahan saat pembayaran dan kemudahan saat refund. Untuk sub kriteria faktor pribadi yaitu reward yang diperoleh dan proses transaksi mudah dan aman.

Untuk alternatif dari pemilihan online travel agency yang akan dipilih terdapat tiga pilihan yaitu Traveloka, Tiket.com, Pegipegi.

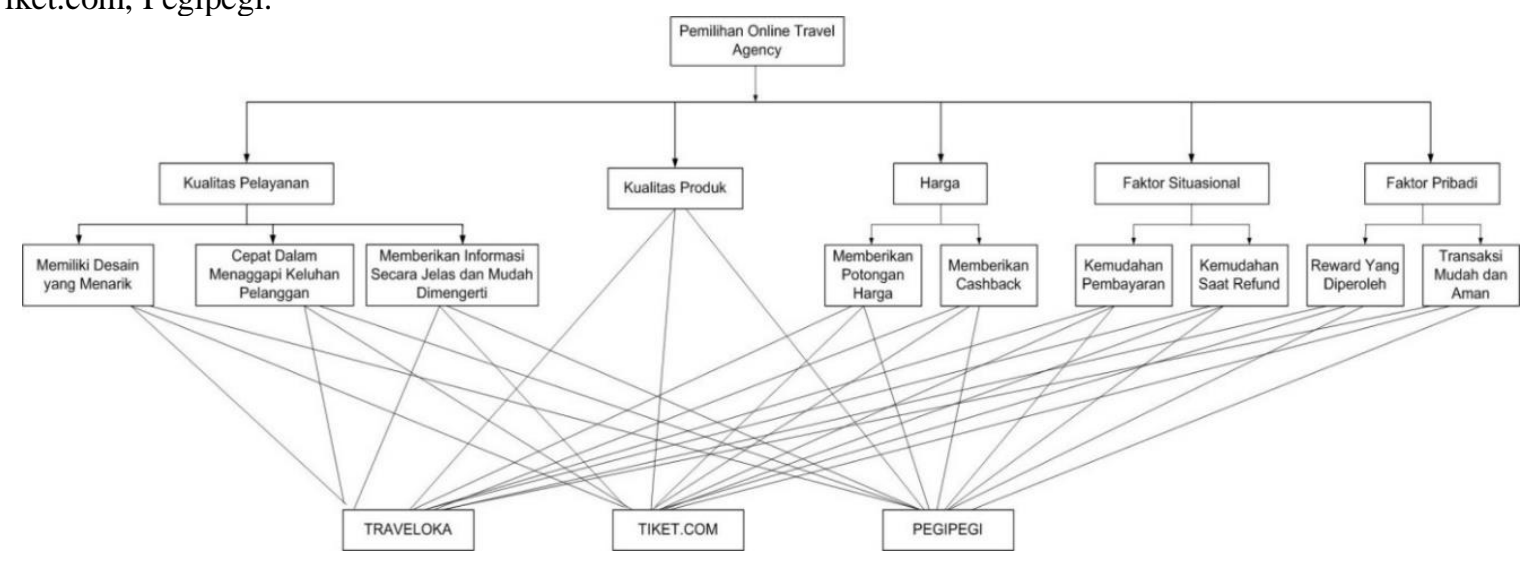

Gambar 2. Dekomposisi Pemilihan Online Travel Agency

\subsection{Perhitungan Kriteria}

Berdasarkan data yang diperoleh dari 400 responden, diperoleh matriks perbandingan berpasangan pada kriteria utama di dapat perbandingan masing-masing kriteria sebagai berikut:

Tabel 4. Matriks Perbandingan Berpasangan Kriteria Utama

\begin{tabular}{cccccc}
\hline & $\begin{array}{c}\text { Kualitas } \\
\text { Pelayanan }\end{array}$ & $\begin{array}{c}\text { Kualitas } \\
\text { Produk }\end{array}$ & Harga & $\begin{array}{c}\text { Faktor } \\
\text { Situasional }\end{array}$ & $\begin{array}{c}\text { Faktor } \\
\text { Pribadi }\end{array}$ \\
\hline Kualitas Pelayanan & 1 & $6 / 5$ & $6 / 5$ & $8 / 3$ & $9 / 5$ \\
Kualitas Produk & $5 / 6$ & 1 & $6 / 5$ & $12 / 5$ & $3 / 2$ \\
Harga & $5 / 6$ & $5 / 6$ & 1 & $12 / 5$ & $3 / 2$ \\
Faktor Situasional & $3 / 8$ & $5 / 12$ & $5 / 12$ & 1 & $3 / 5$ \\
Faktor Pribadi & $5 / 9$ & $2 / 3$ & $2 / 3$ & $5 / 3$ & 1 \\
\hline
\end{tabular}

Tabel 5. Matriks Perbandingan Berpasangan Untuk Kriteria Utama dengan Eigen Vector

\begin{tabular}{ccccccc}
\hline & KPel & KPro & Hrg & Fs & Fp & Eigen Vector \\
\hline Kualitas Pelayanan & 1 & 1.2 & 1.2 & 2.7 & 1.8 & 0.3
\end{tabular}


JURNAL MEDIA INFORMATIKA BUDIDARMA

Volume 4, Nomor 3, Juli 2020, Page 825-833

ISSN 2614-5278 (media cetak), ISSN 2548-8368 (media online)

Available Online at https://ejurnal.stmik-budidarma.ac.id/index.php/mib

DOI $10.30865 /$ mib.v4i3.2268

\begin{tabular}{lllllll} 
Kualitas Produk & 0.8 & 1 & 1.2 & 2.4 & 1.5 & 0.2 \\
Harga & 0.8 & 0.9 & 1 & 2.4 & 1.5 & 0.2 \\
Faktor Situasional & 0.4 & 0.4 & 0.4 & 1 & 0.6 & 0.1 \\
Faktor Pribadi & 0.5 & 0.7 & 0.7 & 1.6 & 1 & 0.2 \\
Total & 3.6 & 4.1 & 4.4 & 10.1 & 6.5 & \\
\hline
\end{tabular}

Berdasarkan nilai eigen vector maka dapat disimpulkan bahwa urutan faktor kriteria utama yang mempengaruhi pemilihan online travel agency adalah kualitas pelayanan 27,7\%, Kualitas Produk 24,1\%, Harga 22,9\%, Faktor Pribadi 15,5\% dan Faktor Situasional 15,5\%. Berdasarkan hasil diatas maka didapatkan nilai konsistensi kriteria adalah:

$C R=\frac{C I}{I R}=\frac{0.00106}{1.12}=0.00095$

Berdasarkan nilai tersebut maka Rasio Konsistensi pada Kriteria Utama adalah kurang dari 0,1 4099/maka dapat diartikan konsisten.

\subsection{Perhitungan Alternatif}

a. Alternatif untuk Memberikan Tampilan Yang Mudah Dimengerti

Tabel 6. Alternatif untuk Memberikan Tampilan Yang Mudah Dimengerti dengan Eigen Vector

\begin{tabular}{llllc}
\hline & Traveloka & Pegipegi & Tiket & Eigen Vector \\
\hline Traveloka & 1 & 2.21367 & 1.81761 & 0.500 \\
Pegipegi & 0.45174 & 1 & 0.85212 & 0.229 \\
Tiket & 0.55017 & 1.46 & 1 & 0.272 \\
Total & 2.00 & 4.39 & 3.67 & \\
\hline
\end{tabular}

Berdasarkan nilai eigen vector maka dapat disimpulkan bahwa urutan alternatif untuk Memberikan Tampilan Yang Mudah Dimengerti adalah Traveloka 50\%, Tiket 27,2\% dan Pegipegi 22,9\%.

b. Alternatif untuk Cepat Dalam Menanggapi Keluhan Pelanggan

Tabel 7. Alternatif untuk Cepat Dalam Menanggapi Keluhan Pelanggan

\begin{tabular}{llllc}
\hline & Traveloka & Pegipegi & Tiket & Eigen Vector \\
\hline Traveloka & 1 & 2.07013 & 1.77226 & 0.489 \\
Pegipegi & 0.48306 & 1 & 0.89620 & 0.240 \\
Tiket & 0.56425 & 1.11582 & 1 & 0.272 \\
Total & 2.05 & 4.19 & 3.67 & \\
\hline
\end{tabular}

Berdasarkan nilai eigen vector maka dapat disimpulkan bahwa urutan alternatif untuk Cepat Dalam Menanggapi Keluhan Pelanggan adalah Traveloka 48,9\%, Tiket 27,2\% dan Pegipegi 24\%.

c. Alternatif untuk Memberikan Informasi Secara Jelas dan Mudah Dimengerti

Tabel 8. Alternatif untuk Memberikan Informasi Secara Jelas dan Mudah Dimengerti dengan EV

\begin{tabular}{llllc}
\hline & Traveloka & Pegipegi & Tiket & Eigen Vector \\
\hline Traveloka & 1 & 2.18771 & 1.94660 & 0.508 \\
Pegipegi & 0.45710 & 1 & 0.91518 & 0.234 \\
Tiket & 0.51372 & 1.09268 & 1 & 0.258 \\
Total & 1.97 & 4.28 & 3.86 & \\
\hline
\end{tabular}

Berdasarkan nilai eigen vector maka dapat disimpulkan bahwa urutan alternatif untuk Memberikan Informasi Secara Jelas dan Mudah Dimengerti adalah Traveloka 50,8\%, Tiket 25,8\% dan Pegipegi 23,4\%.

d. Alternatif untuk Kualitas Produk

Tabel 9. Alternatif untuk Kualitas Produk dengan Eigen Vector

\begin{tabular}{lllll}
\hline & Traveloka & Pegipegi & Tiket & Eigen Vector \\
\hline Traveloka & 1 & 2.27742 & 1.99256 & 0.515 \\
Pegipegi & 0.43909 & 1 & 0.89929 & 0.228 \\
Tiket & 0.50187 & 1.11199 & 1 & 0.256 \\
Total & 1.94 & 4.39 & 3.89 & \\
\hline
\end{tabular}




\section{JURNAL MEDIA INFORMATIKA BUDIDARMA}

Volume 4, Nomor 3, Juli 2020, Page 825-833

ISSN 2614-5278 (media cetak), ISSN 2548-8368 (media online)

Available Online at https://ejurnal.stmik-budidarma.ac.id/index.php/mib

DOI 10.30865/mib.v4i3.2268

Berdasarkan nilai eigen vector maka dapat disimpulkan bahwa urutan alternatif untuk Kualitas Produk adalah

Traveloka 51,5\%, Tiket 25,6\% dan Pegipegi 22,8\%.

e. Alternatif untuk Memberikan Potongan Harga

Tabel 10. Alternatif untuk Memberikan Potongan Harga dengan Eigen Vector

\begin{tabular}{llllc}
\hline & Traveloka & Pegipegi & Tiket & Eigen Vector \\
\hline Traveloka & 1 & 1.88504 & 1.59898 & 0.464 \\
Pegipegi & 0.53049 & 1 & & 0.251 \\
Tiket & 0.62540 & 1.11154 & 1 & 0.285 \\
Total & 2.16 & 4.27 & 3.50 & \\
\hline
\end{tabular}

Berdasarkan nilai eigen vector maka dapat disimpulkan bahwa urutan Alternatif untuk Memberikan Potongan Harga adalah Traveloka 46,4\%, Tiket 28,5\% dan Pegipegi 25,1\%.

f. Alternatif untuk Memberikan Cashback

Tabel 11. Alternatif untuk Memberikan Cashback dengan Eigen Vector

\begin{tabular}{llllc}
\hline & Traveloka & Pegipegi & Tiket & Eigen Vector \\
\hline Traveloka & 1 & 1.80369 & 1.56483 & 0.456 \\
Pegipegi & 0.55442 & 1 & 0.90525 & 0.256 \\
Tiket & 0.63905 & 1.10467 & 1 & 0.287 \\
Total & 2.19 & 3.91 & 3.47 & \\
\hline
\end{tabular}

Berdasarkan nilai eigen vector maka dapat disimpulkan bahwa urutan alternatif untuk Memberikan Cashback adalah Traveloka 45,6\%, Tiket 28,7\% dan Pegipegi $25,6 \%$.

g. Alternatif untuk Kemudahan Saat Pembayaran

Tabel 12. Alternatif untuk Kemudahan Saat Pembayaran dengan Eigen Vector

\begin{tabular}{llllc}
\hline & Traveloka & Pegipegi & Tiket & Eigen Vector \\
\hline Traveloka & 1 & 2.22189 & 1.94409 & 0.509 \\
Pegipegi & 0.45007 & 1 & 0.92476 & 0.234 \\
Tiket & 0.51438 & 1.08136 & 1 & 0.257 \\
Total & 1.96 & 4.30 & 3.87 & \\
\hline
\end{tabular}

Berdasarkan nilai eigen vector maka dapat disimpulkan bahwa urutan alternatif untuk Memberikan Tampilan Yang Mudah Dimengerti adalah Traveloka 50,9\%, Tiket 25,7\% dan Pegipegi 23,4\%.

h. Alternatif untuk Kemudahan Saat Refund

Tabel 13. Alternatif untuk Kemudahan Saat Refund dengan Eigen Vector

\begin{tabular}{llllc}
\hline & Traveloka & Pegipegi & Tiket & Eigen Vector \\
\hline Traveloka & 1 & 1.86392 & 1.73589 & 0.473 \\
Pegipegi & 0.53650 & 1 & 0.90765 & 0.252 \\
Tiket & 0.57607 & 1.10175 & 1 & 0.275 \\
Total & 2.11 & 3.97 & 3.64 & \\
\hline
\end{tabular}

Berdasarkan nilai eigen vector maka dapat disimpulkan bahwa urutan alternatif untuk Kemudahan Saat Refund adalah Traveloka 47,3\%, Tiket 27,5\% dan Pegipegi 25,2\%.

i. Alternatif untuk Reward yang Diperoleh

Tabel 14. Alternatif untuk Reward yang Diperoleh dengan Eigen Vector

\begin{tabular}{lllll}
\hline & Traveloka & Pegipegi & Tiket & $\begin{array}{c}\text { Eigen } \\
\text { Vector }\end{array}$ \\
\hline Traveloka & 1 & 1.94259 & 1.72622 & 0.478 \\
Pegipegi & 0.51478 & 1 & 0.91736 & 0.249 \\
Tiket & 0.57930 & 1.09008 & 1 & 0.274 \\
Total & 2.09 & 4.03 & 3.64 & \\
\hline
\end{tabular}

Berdasarkan nilai eigen vector maka dapat disimpulkan bahwa alternatif untuk Reward yang Diperoleh adalah Traveloka 47,8\%, Tiket 27,4\% dan Pegipegi 24,9\%.

j. Alternatif untuk Proses Transaksi yang Mudah dan Aman 
Tabel 15. Alternatif untuk Proses Transaksi Yang Mudah dan Aman dengan Eigen Vector

\begin{tabular}{lllll}
\hline & Traveloka & Pegipegi & Tiket & $\begin{array}{l}\text { Eigen } \\
\text { Vector }\end{array}$ \\
\hline Traveloka & 1 & 2.13422 & 1.86227 & 0.449 \\
Pegipegi & 0.46856 & 1 & 0.89964 & 0.236 \\
Tiket & 0.53698 & 1.11155 & 1 & 0.265 \\
Total & 2.01 & 4.59 & 3.76 & \\
\hline
\end{tabular}

Berdasarkan nilai eigen vector maka dapat disimpulkan bahwa urutan alternatif untuk Proses Transaksi Yang Mudah dan Aman adalah Traveloka 50\%, Tiket 27,2\% dan Pegipegi 22,95\%.

\subsection{Perhitungan Altenatif Keseluruhan}

Tabel 16. Alternatif Keseluruhan

\begin{tabular}{ccccc}
\hline Overall Composite Weight & Weight & Traveloka & Pegipegi & Tiket.com \\
\hline User Friendly & 0.531 & 0.500 & 0.229 & 0.272 \\
Cepat Dalam Menanggapi Keluhan & 0.226 & 0.489 & 0.240 & 0.272 \\
Info & 0.243 & 0.508 & 0.234 & 0.258 \\
Kualitas Produk & 0.241 & 0.515 & 0.228 & 0.256 \\
Discount & 0.762 & 0.464 & 0.251 & 0.285 \\
Cash Back & 0.238 & 0.456 & 0.256 & 0.287 \\
Pembayaran & 0.740 & 0.509 & 0.234 & 0.257 \\
Refund & 0.260 & 0.473 & 0.252 & 0.275 \\
Reward & 0.313 & 0.478 & 0.249 & 0.274 \\
Keamanan & 0.687 & 0.499 & 0.236 & 0.265 \\
\hline Composite Weight & & 1.961 & 1.018 & 1.141 \\
\hline
\end{tabular}

Jika dalam perhitungan presentase akan didapatkan sebagai berikut:

a. Traveloka $=\frac{1,961}{4,121} \times 100 \%=47,6 \%$

b. Pegipegi $=\frac{1,018}{4,121} \times 100 \%=24,7 \%$

c. Tiket.com $=\frac{1,141}{4,121} \times 100 \%=27,7 \%$

Dari perhitungan tersebut dihasilkan jika Traveloka merupakan Online Travel Agency yang paling diminati oleh para pengguna online travel khususnya masyarakat Kota Bekasi dengan perolehan nilai 1,961 atau sama dengan 47,6 persen. Kemudian pilihan kedua yang banyak diminati adalah Tiket.com dengan perolehan nilai 1,141 atau sama dengan 27,7 persen dan yang terakhir Pegipegi dengan perolehan nilai 1,018 atau sama dengan 24,7 persen.

\section{KESIMPULAN}

Dari hasil penelitian tentang Penetuan Prioritas Pemilihan Online Travel Agency menggunakan metode AHP, maka penulis mengambil kesimpulan sebagai berikut:

1. Hasil penelitian menunjukkan bahwa kriteria Kualitas Pelayanan adalah faktor yang paling penting bagi calon konsumen ketika memilih online travel agent dengan presentase $27,7 \%$, kemudian disusul oleh kriteria kualitas produk $24,1 \%$, kriteria harga $22,9 \%$, kriteria faktor pribadi $15,5 \%$ dan kriteria faktor situasional $9,8 \%$.

2. Pada sub kriteria kualitas pelayanan, faktor yang paling penting adalah memiliki tampilan yang mudah dimengerti dengan presentase $53,1 \%$, selanjutnya memberikan informasi secara jelas dan mudah dimengerti $24,3 \%$ dan yang terakhir cepat dalam menanggapi keluhan pelanggan $22,6 \%$.

3. Pada sub kriteria harga, faktor yang paling penting adalah memberikan potongan harga dengan presentase $76,2 \%$.

4. Pada sub kriteria faktor situasional, faktor yang paling penting adalah kemudahan saat pembayaran dengan presentase $74 \%$.

5. Pada sub kriteria faktor pribadi, faktor yang paling penting adalah proses transaksi mudah dan aman dengan presentase $68,7 \%$.

6. Berdasarkan hasil keseleruhan alternatif yang paling diminati adalah Traveloka dengan presentase 47,6\%, kemudian Tiket.com 27,7\% dan yang terakhir Pegipegi $24,7 \%$.

7. Hasil hipotesa $\mathrm{CR}$ untuk kriteria menunjukkan nilai $\leq 0,1$ atau kurang dari $10 \%$ maka hierarki secara keseluruhan bersifat konsisten, sehingga kesimpulan yang diperoleh dapat diterima, artinya keputusan yang ditetapkan dapat diandalkan.

8. Hasil pengujian hipotesis menunjukkan bahwa hipotesis H1 dapat diterima karena menunjukkan hasil yang sesuai dengan penelitian. 
JURNAL MEDIA INFORMATIKA BUDIDARMA

Volume 4, Nomor 3, Juli 2020, Page 825-833

ISSN 2614-5278 (media cetak), ISSN 2548-8368 (media online)

Available Online at https://ejurnal.stmik-budidarma.ac.id/index.php/mib DOI 10.30865/mib.v4i3.2268

\section{REFERENCES}

[1] Rezgo, "Tour \& Activity Industry Terms What is an OTA ? Retrieved May 26, 2019," Rezgo, 2018. [Online]. Available: https://www.rezgo.com/glossary/ota.

[2] H. Indah, "Travel, Kini Jadi Kebutuhan Primer Orang Indonesia," www.beritasatu.com, 2019. [Online]. Available: https://www.beritasatu.com/destinasi/306026-travelkini-jadi-kebutuhan-primer-orang-indonesia.html.

[3] L. Hendriyati, "Pengaruh online travel agent terhadap pemesanan kamar di hotel mutiara malioboro yogyakarta," $J$. Media Wisata, vol. 17, pp. 1090-1099, 2019.

[4] F. Rangkuti, Customer Service Satisfaction \& Call Center Berdasarkan ISO 900. Jakarta: PT Gramedia Pustaka Utama, 2013.

[5] T. Hendratono and A. D. Santosa, "Pengaruh Persepsi Harga Dan Kualitas Layanan Terhadap Keputusan Pembelian Pada Online Travel Agent Traveloka Di Jakarta," J. Hosp. dan Pariwisata, vol. 3, no. 2, pp. 362-374, 2017.

[6] R. Kwanto and J. Arliansyah, "Analisis Pemilihan Moda Transportasi Umum Antara Transportasi Umum Konvensional Dan Transportasi Umum,” J. Arjuna, vol. 4247, 2016.

[7] D. Nofriansyah and S. Defit, Multi Criteria Decision Making (MCDM) pada Sistem Pendukung Keputusan, 1 st ed. Yogyakarta: Deepublish, 2017.

[8] E. Sestri and Husnayetti, "Penggunaan Metode Analytical Hierarchy Process ( AHP ) dalam Analisis Faktor-Faktor yang Mempengaruhi Penggunaan Transportasi Online," SEMNASTEKNOMEDIA ONLINE, pp. 31-36, 2018.

[9] H. Purwanto, "Pemilihan Aplikasi Transportasi Ojek Online dengan Menggunakan Metode AHP dan TOPSIS," KNIT-2 Nusa Mandiri, pp. 219-224, 2016.

[10] A. D. Nainggolan, "Pengaruh Iklan , Harga , dan E-Service Quality Terhadap Customer Loyalty pada Pengguna Jasa Online Travel Agent ( Studi Kasus pada Pengguna Traveloka \& Tiket . com di Medan ),” 2019.

[11] F. Sari, Metode Dalam Pengambilan Keputusan. Yogyakarta: Deepublish, 2019.

[12] Sugiyono, Metode Penelitian Kuantitatif, Kualitatif, Dan R\&D. Bandung: Alfabeta, 2017.

[13] S. Siregar, Statistika Deskriptif Untuk Penelitian: Dilengkapi Perhitungan Manual dan Aplikasi SPSS, 1st ed. Depok: PT RajaGrafindo Persada, 2014. 